\title{
Bromocriptine and the Clinical Spectrum of Parkinson's Disease
}

\author{
Richard J. Riopelle
}

\begin{abstract}
As the direct agonist with the widest clinical use, bromocriptine provides a unique window into the clinical spectrum of Parkinson's disease. The efficacy of bromocriptine for therapy of de novo Parkinson's disease has recently been confirmed using a double-blind design with L-Dopa (Sinemet). Over a period of 5.5 months, bromocriptine was found to be as effective as L-Dopa in reducing the functional and neurological disability of Parkinson's disease. This study complements others and demonstrates a role for bromocriptine as de novo therapy. A longitudinal study comparing bromocriptine with L-Dopa is underway, but previous observations with bromocriptine suggest modest, transient beneficial effects with significantly less fluctuation of disability and less dyskinesia when used alone or in combination with L-Dopa. The transient benefits of bromocriptine on progressive disability suggest that both pre-and post-synaptic defects are eventually involved in Parkinson's disease. While agonists with improved efficacy and minimal side effects are required for symptomatic treatment of Parkinson's disease, strategies to protect pre- and post-synaptic neuron populations against progressive dysfunction must be developed.
\end{abstract}

RÉSUMÉ: La bromocriptine et l'éventail clinique de la maladie de Parkinson. En tant qu'agoniste directe dont l'utilisation clinique est la plus étendue, la bromocriptine nous donne un aperçu unique de l'éventail clinique de la maladie de Parkinson.

L'efficacité de la bromocriptine dans le traitement de novo de la maladie de Parkinson a été confirmé récemment au moyen d'un essai thérapeutique en double insu avec la L-Dopa (Sinemet). Sur une période de 5.5 mois, nous avons constaté que la bromocriptine était aussi efficace que la L-Dopa pour diminuer l'invalidité fonctionnelle et neurologique de la maladie de Parkinson. Cette étude complémente d'autres études et démontre que la bromocriptine a un rôle à jouer dans le traitement de novo de cette maladie. Une étude longitudinale comparant la bromocriptine à la L-Dopa est en cours; cependant, des observations antérieures sur la bromocriptine suggèrent des effets bénéfiques transitoires modestes, avec présence de fluctuations de l'invalidité et de dyskinésies significativement moindres quand ce médicament est utilisé seul ou en combinaison avec la L-Dopa.

Les effets bénéfiques transitoires de la bromocriptine sur l'invalidité progressive suggèrent que des défauts préet post-synaptiques sont éventuellement en cause dans la maladie de Parkinson. Même si des agonistes avec une efficacité améliorée et des effets secondaires réduits au minimum sont nécessaires pour le traitement symptomatique de la maladie de Parkinson, des stratégies pour protéger les populations de neurones pré- et post-synaptiques contre une dysfonction progressive doivent être développées.

Can. J. Neurol. Sci. 1987; 14:455-459

Since its introduction to the therapeutic regimen of Parkinson's discase in $1974,{ }^{1}$ bromocriptine has secured a position as adjuvant therapy to L-Dopa. Fluctuations in Parkinson's disease symptoms have been lessened by adjuvant therapy at least in part because addition of bromocriptine with its D-2 dopamine receptor agonist effects has permitted reduction of doses of L-Dopa.

The limited time span of L-Dopa effectiveness and the onset of unmodifiable motor and mental side effects of therapy in Parkinson's disease have been the impetus to delay therapy with L-Dopa until the failure of other therapeutic modalities had occurred. It is argued, however, that progressive disability is related only to progression of disease, and that the best response to L-Dopa will be seen with early therapy.

While these controversies persist, a pragmatic approach might be that introduction of therapy with L-Dopa should occur when disability of Parkinson's disease is interfering with work, recreation, or interpersonal relationships, and when other modalities used for de novo therapy no longer control the disability. ${ }^{2}$

Experience with bromocriptine as de novo treatment of Parkinson's disease is limited to a few hundred patients. The consensus of investigators using bromocriptine as long-term de novo therapy suggests that, while less dyskinesia and less fluctuations in disability are observed, clinical effectiveness of the agonist is modest, transient, and often limited by doserelated side effects. To complement earlier clinical observations, the first phase of a long-term multicentre study comparing bromocriptine and L-Dopa (as Sinemet) as de novo therapy using a double-blind randomized design has recently been completed.

As the direct agonist with the widest clinical use, bromocriptine provides a unique window into the clinical spectrum of Parkinson's disease. One of the implications from studies of the efficacy of bromocriptine in the various stages of Parkinson's disease is 
that new strategies of therapy for Parkinson's disease must be developed.

\section{METHODS}

\section{Study Design}

Patients with idiopathic Parkinson's disease who had not been exposed previously to anti-Parkinson therapy (other than anticholinergics) were assigned randomly (intracentre) to the two treatment groups in seven centres. The study of twentythree weeks' duration was divided into three consecutive phases consisting of (i) a two-week baseline phase during which patients were assessed twice; (ii) a titration phase lasting a maximum of fifteen weeks during which medication dosage provided as identical capsules was incremented following assessment every three weeks until stable improvement or a maximum of $30 \mathrm{mg}$ per day of bromocriptine or $300 / 75 \mathrm{mg}$ of Sinemet (whichever came first) was achieved: (iii) a maintenance period of six weeks' duration where the medication dosage was held constant. For the first three weeks of treatment, daily dosages of bromocriptine and L-Dopa were $5 \mathrm{mg}$ and $50 \mathrm{mg}$ respectively. Stable improvement was defined as lack of further improve-

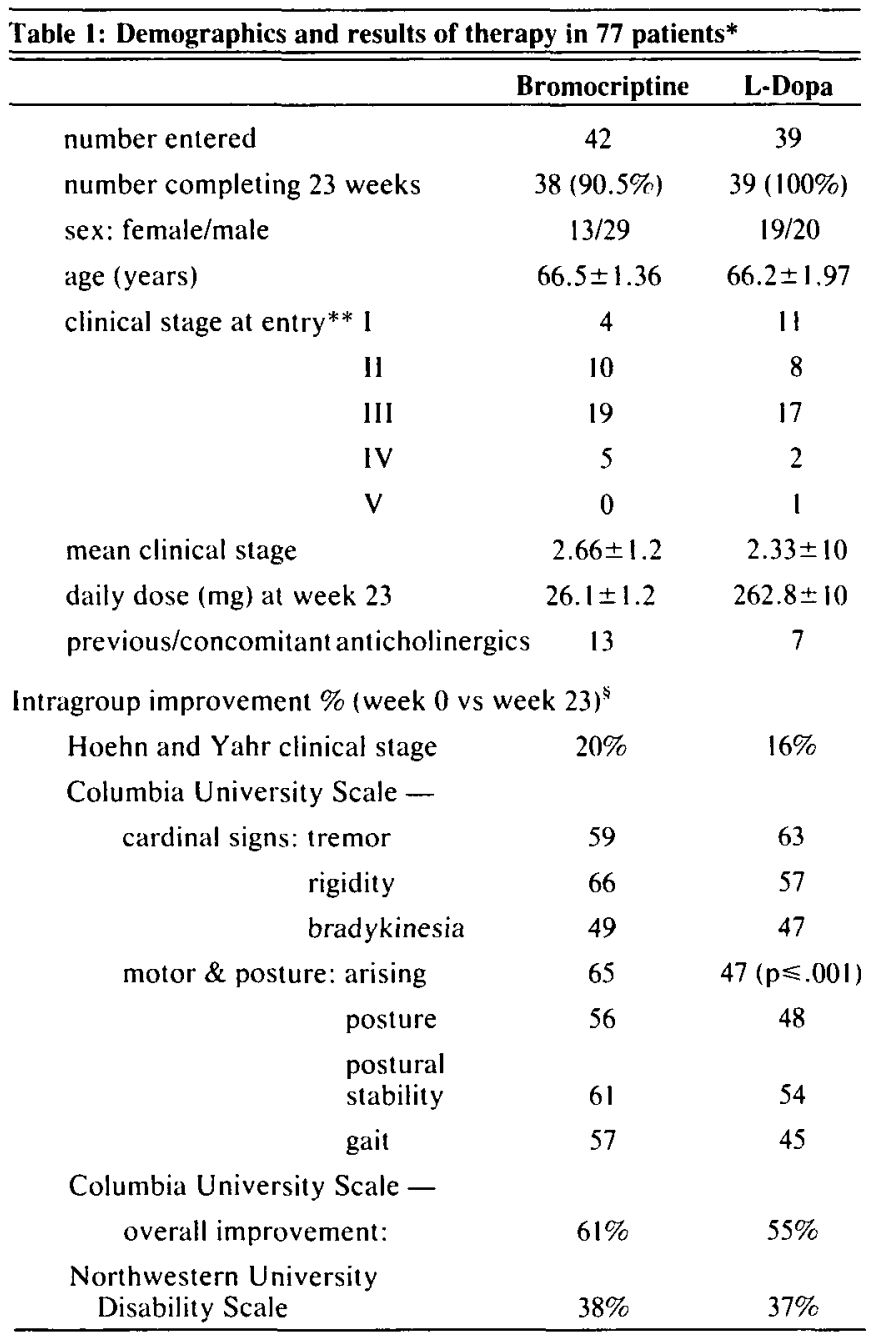

* Riopelle RJ, Gawel M, Libman I. King DB, McLean DR, Paulseth R, Raphy B, Bouchard S (in preparation)

** includes only those completing study

$\S$ significant at $p \leqslant .0001$ unless noted ment when dose was increased for two consecutive titration visits. At the end of the maintenance period, patients were classified as responders or non-responders, based upon clinical response at the tolerated or maximal dose of medication.

\section{Analysis}

Parameters used to assess efficacy were the clinical status of Hoehn and Yahr, ${ }^{3}$ the Columbia University Scale,${ }^{4}$ and the Northwestern University Disability Scale. ${ }^{5}$ Side effects of medications were reported at every visit, and the safety of the medications was monitored by periodic evaluation consisting of physical examination including vital signs, hematological and biochemical parameters, urinalysis, chest X-ray, and electrocardiogram.

All data were analyzed using the S.A.S. Package; the significance level for inferential tests was fixed at $1 \%$.

\section{RESULTS}

The seven centres participating in the study entered eightyone patients; forty-two patients were assigned to the bromocriptine group, and thirty-nine to the L-Dopa group. Four patients on bromocriptine dropped out of the study, leaving a total of seventy-seven patients (thirty-eight bromocriptine, thirty-nine L-Dopa) completing the twenty-three week trial.

Table 1 summarizes the patient demographics and results of treatment in the two groups at twenty-three weeks. At the onset of the study, patient demographics were similar in the two groups, and the entry clinical stage of the patients completing the twenty-three week study showed no significant differences. The mean of the entry clinical stage was 2.66 for the bromocriptine group and 2.33 for the L-Dopa group. No statistically significant difference was found between the two groups for any parameter of the Columbia University Scale or the Northwestern University Disability Scale (NUDS) at entry.

At the end of twenty-three weeks, the thirty-eight bromocriptine patients were taking $26 \pm 1.2 \mathrm{mg}$ (mean \pm s.e.m.), and the thirty-nine L-Dopa patients were taking a dose of $262.8 \pm 10 \mathrm{mg}$ of L-Dopa (in Sinemet).

The four patients who dropped out of the study were in the bromocriptine group. As a group, these patients left the study before the dose was incremented to $10 \mathrm{mg}$ per day at the end of the first three weeks of the fifteen-week titration phase.

When comparisons between scores at week 0 and the end of the study were made, improvements in the clinical stage of patients was $20 \%$ for bromocriptine and $16 \%$ for L-Dopa. Overall improvement on the Columbia University Scale was $61 \%$ and $55 \%$ for bromocriptine and L-Dopa respectively, while in the NUDS, overall improvement was $38 \%$ and $37 \%$ respectively. Within each group there was statistically significant improvement in all parameters of the two multiparameter rating scales. The level of significance of the observations summarized in Table I within the two groups was high. No significant differences were found between the two groups for clinical stage, overall assessments with the Columbia University Scale and NUDS, or cardinal signs as scored using the Columbia University Scale.

For the seventy-seven patients completing the twenty-three weeks of the study, dyskinesias and fluctuations in disability were absent, side effects were tolerable, and laboratory assessments did not necessitate discontinuation. 


\section{Discussion}

\section{Bromocriptine in Early Parkinson's Disease}

While the present study complements and extends observations on the efficacy of bromocriptine in de novo Parkinson's disease, direct comparison with other studies is tenuous at this time. In general terms, however, and in agreement with numerous observations, bromocriptine has been shown to be an effective anti-Parkinson agent. The data reported here are derived from the first large study to compare the efficacy and tolerance of bromocriptine with L-Dopa in a double-blind fashion in patients who have not been exposed previously to dopaminergic agents. Over a time frame of twenty-three weeks, bromocriptine at a mean dose of $26.1 \mathrm{mg}$ was as effective as L-Dopa at a mean dose of $262.8 \mathrm{mg}$ in improving clinical stage and the neurological and functional disabilities of Parkinson's disease. The doses of bromocriptine and L-Dopa chosen for the present study reflected current usage of the direct agonist, the trend to lower doses of L-Dopa (with decarboxylase inhibitors), and a previously suggested equipotent milligram dose ratio of 1 to 10 . $^{\text {sa,b }}$

Previously reported studies of bromocriptine in de novo patients have not been designed to compare in a blinded fashion one agent with the best available alternative. Some of these studies have concentrated on long-term efficacy of the direct agonist, and some have compared in an unblinded design the effects of bromocriptine with doses of L-Dopa that were usually higher than those used in the present study.

Table 2 denotes data from de novo studies of bromocriptine that could be analyzed in such a way as to facilitate comparison with the short-term results of the present study. ${ }^{6.7 .8 .9 .10 .11}$

The present study and six previous de novo studies demonstrate the overall efficacy of bromocriptine as a de novo antiParkinson agent. When compared in a double-blind design with L-Dopa at milligram dose ratios of approximately $1: 10$, bromo- criptine and L-Dopa are equipotent, at least for periods up to approximately six months in patients with moderate disability.

On the basis of studies with bromocriptine and L-Dopa in de novo Parkinson's disease, Rinne ${ }^{12}$ has concluded that a combination of L-Dopa and bromocriptine provides the best control of Parkinson's disease disability with less fluctuation and dyskinesia in long-term follow-up. The present study and the six earlier investigations referred to here would suggest that, for moderate Parkinson's disease, bromocriptine can provide adequate control until such time that progressive clinical disability requires addition of L-Dopa to the therapeutic regimen.

\section{The Problem of Progressive Disability in Parkinson's Disease}

Continuing analysis of patients entered in the present study which has now entered the open label phase will permit assessment of long-term efficacy of bromocriptine in Parkinson's disease. However, published data on the long-term efficacy of this agonist do not provide cause for optimism. As summarized in Table 3, Rinne ${ }^{12}$ reported only $15 \%$ improvement on the Columbia University Scale in twenty-one patients after thirtysix months on the drug. At twelve months, Lees and Stern ${ }^{13}$ observed that $44 \%$ of patients did not achieve $25 \%$ reduction in symptoms, while Rascol et al ${ }^{14}$ observed $27 \%$ improvement at twelve months in twenty-nine patients on a mean dose of $54.7 \mathrm{mg}$. At the end of thirty months, Grimes and Delgado ${ }^{8}$ were able to adequately control Parkinson disability in only three patients. Similar data have been reported by Hardie et al ${ }^{15}$ at sixty months. Alternatively, at the end of twenty-four months, Teychenne et al ${ }^{10}$ witnessed $31 \%$ improvement in twelve patients with no significant change in disability at six, twelve, eighteen, and twenty-four months, even though the mean dose of bromocriptine increased from $11.7 \mathrm{mg}$ at six months to $14 \mathrm{mg}$ at twenty-four months.

\begin{tabular}{|c|c|c|c|c|c|c|}
\hline Author & $\begin{array}{c}\text { Mean dose } \\
(\mathrm{mg})\end{array}$ & $\begin{array}{c}\text { Time } \\
\text { (mos.) }\end{array}$ & No. & Stage & $\begin{array}{c}\% \\
\text { Improvement } \\
\end{array}$ & Rating Scale \\
\hline
\end{tabular}

$\S$ clinical stage of Hoehn and Yahr

* cardinal signs: tremor, rigidity, bradykinesia

** approximate maximum based on increment of $1.25 \mathrm{mg} /$ week up to $30 \mathrm{mg} / \mathrm{day}$

+ initial peak effect

$\dagger \quad$ Riopelle RJ, Gawel M, Libman I, King DB, McLean DR, Paulseth

$\mathrm{R}$, Raphy B, Bouchard S (in preparation)

\begin{tabular}{lccccl}
\hline Table 3: Long-term results of bromocriptine in de novo Parkinson's disease & \\
\hline \hline & $\begin{array}{c}\text { Mean Dose } \\
(\mathbf{m g})\end{array}$ & $\begin{array}{c}\text { Time } \\
(\mathbf{m o s})\end{array}$ & $\begin{array}{c}\text { No. of } \\
\text { Patients }\end{array}$ & Stage & Results \\
Author & 28 & 36 & 21 & 2.8 & $15 \%$ improvement on Columbia scale \\
\hline Rinne $^{12}$ & 53.7 & 12 & 29 & 1.9 & $27 \%$ improvement using author's grading system \\
Rascol et al $^{14}$ & 14 & 24 & 12 & 2.7 & $31 \%$ improvement in cardinal signs \\
Teychenne et al $^{10}$ & 13.2 & 30 & 13 & 2 & $23 \%$ taking bromocriptine alone \\
Grimes \& Delgado $^{8}$ & 40 & 12 & 50 & 2.3 & $\begin{array}{l}44 \% \text { did not achieve 25\% improvement; 18\% showed } \\
\text { sustained benefit }\end{array}$ \\
Lees \& Stern & & & & &
\end{tabular}


Published data suggest that bromocriptine, when used as adjuvant therapy with L-Dopa in de novo Parkinson's disease patients, ${ }^{12}$ or when added to L-Dopa therapy as fluctuations and dyskinesias appear, reduces these side effects and probably extends the period of effectiveness of therapy. De novo studies with the agonist as the only therapy for Parkinson's disease for periods greater than one to two years. ${ }^{8.10 .12-14}$ suggest that, while the appearance of fluctuations and dyskinesias is significantly less than with L-Dopa therapy, anti-Parkinson effects are modest at best and are not sustained. Thus, a combination of bromocriptine and L-Dopa, as suggested by Rinne, ${ }^{12}$ appears to be indicated to maximize efficacy of therapy while minimizing side effects.

The limited time span of L-Dopa effectiveness and the appearance of unmodifiable side effects of this therapy can likely be explained in part by progressive loss of nigrostriatal decarboxylase activity. Elucidation of mechanisms of MPTP toxicity have contributed to suggestions that the MAO-B system of striatal glia and the avid monoamine reuptake system of the nigrostriatal projection might provide a setting in which dopamine oxidation with free radical generation could set in place a nigrostriatal autotoxic mechanism that might accelerate disease by further compromise of the pre-synaptic projection. ${ }^{16-23}$ However, the suggestion that L-Dopa therapy contributes to the progressive disability of Parkinson's disease is controversial. Markham and Diamond ${ }^{2}$ have presented data to suggest that disease severity and not duration of L-Dopa therapy determines disability and the appearance of unmodifiable side effects of treatment. These conclusions are supported by the observations of MPTP-exposed patients with Parkinsonism..$^{24}$ Muenter ${ }^{25}$ has argued that the best response to L-Dopa will be seen with early therapy, while Hoehn ${ }^{26}$ has observed that postponing treatment increases the incidence of non-responsiveness to available drugs.

The observation that the direct agonist bromocriptine has only transient beneficial influence on the progressive disability of late stage Parkinson's disease argues that progressive loss of pre-synaptic nigrostriatal influence cannot explain completely the features of advanced treated disease. The failure of postsynaptic striatal systems could be implicated as a partial explanation for this non-responsiveness to therapy. A gradual alteration or loss of a D-2 dopamine receptor could explain in part the progressive loss of efficacy of L-Dopa and the failure of the D-2 receptor agonists to effectively replace L-Dopa in late stage disease. The modest influence of drug holidays ${ }^{27.28}$ and the failure of repeated drug withdrawal to restore responsiveness to therapy would suggest that D-2 receptor down regulation is likely playing only a small role in non-responsiveness. These clinical observations in late stage disease are suggestive of a loss of post-synaptic D-2 receptor-bearing neurons. In patients who are manifesting fluctuations in disability on L-Dopa therapy, the response to administration of apomorphine indicates that dopamine receptor is available and suggests that the "off" period is a supply-side problem $;^{29}$ however, the response of these patients to pyridostigmine would suggest that striatal cholinergic synaptic mechanisms may be hypersensitive. ${ }^{29}$ These observations and the findings of some groups that choline acetyltransferase (ChAT) levels in striatum are decreased ${ }^{30.31}$ or unchanged ${ }^{32}$ in Parkinson's disease could suggest a drop-out of striatal post-synaptic cholinergic neurons in late stage disease which might explain loss of efficacy of anti-Parkinson therapy and the clinical findings of suspected cholinergic hypersensitivity. The intriguing observations that loss of responsiveness to therapy in Parkinson's disease is frequently associated with the appearance of dementia, and that dementia is commonly associated with the disease, ${ }^{33.34}$ might argue that these groups of patients suffer from a diffuse forebrain cholinergic disturbance.

Emerging concepts of trans-synaptic neuronal influence may provide partial explanation for the loss of response to treatment due to loss of post-synaptic neuronal populations. A declining pre-synaptic nigrostriatal input might result in loss of transsynaptic trophic influence and/or reduced modulation of selective pressures on post-synaptic striatal neurons by the large cortical excitatory amino acid input (glu/asp), ${ }^{35}$ endogenous excitotoxins, or $\mathrm{Ca}^{++}$fluxes.

At this point, observations ${ }^{29.30 .31 .32}$ suggesting a drop-out of striatal post-synaptic cholinergic neurons and/or their extensive extrastriosomal neuropil ${ }^{36}$ requires confirmation by careful morphometric analysis. Regional neurotransmitter receptor and neurotransmitter-specific enzyme quantification may not provide a sensitive indicator of the integrity of individual postsynaptic neurons, some of which may be degenerating because of loss of trans-synaptic influence, and some of which may be responding transiently to denervation by up-regulation responses in the same time frame.

If, as is suggested for L-Dopa, the price of a highly efficacious symptomatic treatment of Parkinson's disease disability is the development of side effects such as fluctuations in disability and dyskinesias, improved long-term symptomatic therapy may prove to be difficult to achieve. However, since disease severity appears to be a major factor in the development of side effects, protection of the integrity of remaining nigral neurons and post-synaptic D-2 receptor-bearing neuron populations should be important goals of future studies. In this regard, pharmaceuticals active on MAO-B systems, monoamine reuptake inhibitors, and free-radical scavengers might have symptomatic and/or protective effects in Parkinson's disease. Additionally, neurotrophic factors may have a role in protection of pre- and post-synaptic neurons. The recent observations that striatal cholinergic neurons bear high affinity Nerve Growth Factor (NGF) receptors ${ }^{37.38}$ and respond to pharmacological doses of the protein ${ }^{39}$ provide justification for studies of the role of NGF in MPTP models of Parkinsonism.

\section{ACKNOWLEDGEMENTS}

Stephanie McCaughey produced the manuscript. Some of the studies referred to in the manuscript were supported by a MRC Canada grant to the author. Sandoz (Canada) supported the double-blind study.

\section{REFERENCES}

1. Calne DB, Teychenne PF, Claversia LE, et al. Bromocriptine in Parkinsonism. Br Med J 1974; 4: 442-444.

2. Markham $\mathrm{CH}$, Diamond SG. Long-term follow-up of early dopa treatment in Parkinson's disease. Ann Neurol 1986; 19: 365-372.

3. Hoehn MM, Yahr MD. Parkinsonism: onset, progression, and mortality. Neurology 1967; 17: 427-442.

4. Duvoisin RC. The evaluation of extrapyramidal disease. In: de Ajuriagena J, ed. Monamines: Noyaux Gris Centraux et Syndrome de Parkinson. Paris: Masson, 1970: 313-325.

5. Canter JC, De La Torre R, Mier M. A method for evaluating disability in patients with Parkinson's disease. J Neur Ment Dis 1961: 7: 133-143. 
5a. Calne DB, Williams AC, Nutt JG, et al. Ergot derivatives for Parkinsonism. Med J Austr Spec Suppl 1978; 2(3): 25-26.

5b. Lees AJ, Haddad S, Shaw KM, et al. Bromocriptine in Parkinsonism: a long-term study. Arch Neurol 1978; 35: 503-505.

6. Rinne UK, Marttila M. Brain dopamine receptor stimulation and the relief of Parkinsonism: relationship between bromocriptine and levodopa. Ann Neurol 1978; 4: 263-267.

7. Devathasan G, Chong PN, Puvanendran K, et al. Low dose bromocriptine therapy in severe Parkinson's disease. Clin Neuropharmacol 1984; 7: 231-238.

8. Grimes JD, Delgado MR. Bromocriptine: problems with low dose de novo therapy in Parkinson's disease. Clin Neuropharmacol 1985; 8: 73-77.

9. Olanow $\mathrm{CW}$, Alberts MJ. Low dose bromocriptine in previously untreated Parkinson's disease. In: Fahn S, Marsden CD, Jenner P, Teychenne P, eds. Recent Developments in Parkinson's Disease. New York: Raven Press, 1986; 273-278.

10. Teychenne PF, Bergsrud D, Elton RL, Racy A. Bromocriptine: long-term low-dose therapy in Parkinson's disease. Clin Neuropharmacol 1986; 9: 138-145.

11. Staal-Schreinemachers AL, Wesseling H, Kamphius DJ, et al. Low dose bromocriptine therapy in Parkinson's disease: double blind placebo-controlled study. Neurology 1985; 36: 291-293.

12. Rinne UK. Combined bromocriptine-levodopa therapy early in Parkinson's disease. Neurology 1985; 35: 1196-1198.

13. Lees AJ, Stern GM. Sustained bromocriptine therapy in previously untreated patients with Parkinson's disease. J Neurol Neurosurg Psychiat 1981; 44: 1021-1023.

14. Rascol A, Montastruc JL, Rascol O. Should dopamine agonists be given early or late in the treatment of Parkinson's disease? Can J Neurol Sci 1984; 11 (Suppl 1): 229-232.

15. Hardie RJ, Lees AJ, Stern GM. The controversial role of bromocriptine in Parkinson's disease. Clin Neuropharmacol 1985; 8: 150-155.

16. Langston JW. MPTP and Parkinson's disease. Trends in Neurosci 1985; 8: 79-83.

17. Langston JW, Irwin I. MPTP: current concepts and controversies. Clin Neuropharmacol 1986; 9: 485-507.

18. McDaniel KD. Clinical pharmacology of monoamine oxidase inhibitors. Clin Neuropharmacol 1986; 9: 207-234.

19. Barbeau A. Etiology of Parkinson's disease: a research strategy. Can J Neurol Sci 1984; 11: 24-28.

20. Cohen G. The pathobiology of Parkinson's disease: biochemical aspects of dopamine neuron senescence. J Neural Transm 1984; 19: 89-103.

21. Birkmayer W, Knott J, Riederer P, et al. (-) Deprenyl leads to prolongation of L-dopa efficacy in Parkinson's disease. Mod Probl Pharmacopsych 1983; 19: 215-219.

22. Carlsson A, Winblad B. Influence of age and time interval between death and autopsy on dopamine and 3-methoxytyramine levels in human basal ganglia. J Neural Transm 1976; 38: 271-276.
23. Riederer $\mathbf{P}$, Wuketich ST. Time course of nigro-striatal degeneration in Parkinson's disease. J Neural Transm 1976; 38: 277-301.

24. Langston J, Ballard P. Parkinsonism induced by I-methyl-4-phenyl1,2,3,6 tetrahydropyridine (MPTP): implications for treatment and the pathogenesis of Parkinson's disease. Can J Neurol Sci 1984; 11 (Suppl. 11): 160-165.

25. Muenter MD. Should levodopa therapy be started early or late? Can J Neurol Sci 1984; 11 (Suppl 1): 195-199.

26. Hoehn MM. Parkinsonism treated with levodopa progression and mortality. J Neural Transm Suppl 1983; 19: 253-264.

27. Kofman OS. Are levodopa drug holidays justified? Can J Neurol Sci 1984; 11 (Suppl 1): 206-209.

28. Kaye JA, Feldman RG. The role of $L$-dopa holiday in the long-term management of Parkinson's disease. Clin Neuropharmacol 1986; 9: $1-13$.

29. Clough CG, Bergmann KJ, Yahr MD. Cholinergic and dopaminergic mechanisms in Parkinson's disease after long-term L-dopa administration. In: Hassler RG, Christ JF, eds. Advances in Neurology 40. New York: Raven Press, 1983: 131-140.

30. Reisine TD, Fields JZ, Yamamura HI, et al. Neurotransmitter receptor alterations in Parkinson's disease. Life Sci 1977; 21: 335-343.

31. Lloyd KG, Mohler $\mathbf{H}$, Hertz $\mathbf{P H}$, et al. Distribution of cholineacetyltransferase and glutamic acid decarboxylase within the substantia nigra and other brain regions from control and parkinsonian brain. Lancet 1975; 2: 623-624.

32. McGeer PL, McGeer EG. Fibiger HC. Glutamic acid decarboxylase and cholineacetyltransferase in Huntington's chorea and Parkinson's disease. Lancet 1973; 2: 623-624.

33. Rajput AH, Offord K. Beard CM, et al. Epidemiological survey of dementia in parkinsonism and control populations. I $n$ : Hassler RJ, Christ JF, eds. Advances in Neurology 40. New York: Raven Press, 1983: 229-234.

34. Mayeux R, Stern Y, Rosen J, et al. Depression, intellectual impairment and Parkinson's disease. Neurology 1981; 31: 645-650.

35. McGeer EG, Staines WA, McGeer PL. Neurotransmitters in the basal ganglia. Can J Neurol Sci 1984; 11 (Suppl 1): 89-99.

36. Graybiel AM, Baughman RW, Eckenstein F. Cholinergic neuropil of the striatum observes striosomal boundaries. Nature 1986: 323: 625-627.

37. Richardson PM, Verge Issa VMK, Riopelle RJ. Distribution of neuronal receptors for nerve growth factor in the rat. J Neurosci 1986; 6: 2312-2321.

38. Riopelle RJ, Richardson PM, Verge VMK. Distribution and characteristics of Nerve Growth Factor binding on cholinergic neurons of rat and monkey forebrain. Neurochem Res 1987; in press.

39. Mobley WC, Rutkowski JL, Tennekoon GI, et al. Choline acetyltransferase activity in striatum of neonatal rats increased by nerve growth factor. Science 1985: 229: 284-287. 